\title{
The Globalization of the Wine Industry in Hong Kong : A Local and Global Perspective
}

\author{
Ho, Hang Kei \\ Bloomsbury Academic \\ 2019
}

Ho , H K 2019, The Globalization of the Wine Industry in Hong Kong : A Local and Global Perspective . in D Inglis \& A-M Almila (eds), The Globalization of Wine . Bloomsbury pÿAcademic , London , pp. 133150 . https://doi.org/10.5040/9781474265027.ch-008

http://hdl.handle.net/10138/316917

https://doi.org/10.5040/9781474265027.ch-008

acceptedVersion

Downloaded from Helda, University of Helsinki institutional repository.

This is an electronic reprint of the original article.

This reprint may differ from the original in pagination and typographic detail.

Please cite the original version. 


\section{Publication information}

Chapter title

Book title

Author

Editors

Affiliation

Year of publication

DOI
The Globalization of the Wine Industry in Hong Kong: A Local and Global Perspective

The globalization of wine

Hang Kei Ho

David Inglis and Anna-Mari Almila

Department of Technology and Society Studies, Faculty of Arts and Social Sciences, Maastricht University, The Netherlands

2019

10.5040/9781474265027.ch-008

\section{To cite this publication}

Ho, H.K. (2019). The Globalization of the Wine Industry in Hong Kong: A Local and Global Perspective. In D. Inglis, \& A-M. Almila (Eds.), The Globalization of Wine (pp. 133-150). London: Bloomsbury, DOI:10.5040/9781474265027.ch-008

\section{Note}

The accepted version may differ from the final printed version. 


\section{Introduction}

In 2011, the global wine industry was stunned when the Financial Times reported that more than half of the global revenues of the fine and rare wine trade were generated through auctions that took place in Hong Kong, overtaking New York to become the most valuable wine auction hub (Lister 2011). By 2018, the Hong Kong wine world had further developed. An auction hosted by Christie's in Hong Kong witnessed 1,700 lots of rare vintages which were sold at $\$ 14.5$ million (HK\$113 million, $£ 9.81$ million) ${ }^{1}, \$ 1.5$ million more than the original estimate (Loos 2018). A particular lot of twelve-bottle 1982 Château Le Pin was auctioned for \$206,000 (HK\$1.60 million, £139,000).

One might think that wine has long been a popular drink in Hong Kong, but the wine culture there is relatively young. Until 2007 , wine was only available in a limited range because it was expensive due to its high duty at 80 per cent. High taxation resulted in high retail prices, and coupled with the specific knowledge required for consumption, wine remained a drink for wealthy consumers. After years of lobbying by local businesses, the Hong Kong government reduced the wine duty to 40 per cent in February 2007, and since February 2008, wine duty has been completely withdrawn.

One might think that wine has long been a popular drink in Hong Kong, but the wine culture there is relatively young. Until 2007 , wine was only available in a limited range because it was expensive due to its high duty at 80 per cent. High taxation resulted in high retail prices, and coupled with the specific knowledge required for consumption, wine remained a drink for wealthy consumers. After years of lobbying by local businesses, the Hong Kong government reduced the wine duty to 40 per cent in February 2007, and since February 2008, wine duty has been completely withdrawn.

Meanwhile, during the global financial crisis in 2007, the sales of fine and rare wine for the North American and Western European markets dropped significantly. However, the global wine trade remained largely unaffected as the focus shifted to South East Asia instead. In 2008, \$8.20 million (HK\$ 63.8 million, £5.55 million) of the finest and rarest wines were sold at a single auction hosted by Acker Merrall \& Condit in Hong Kong, in which more than five world auction records were broken (Pomfret 2008). Some of the lots included the 1990 Domaine de la Romanée-Conti, magnums of 1966, 1973 and 1976 Dom Perignon, as well as 1945 Mouton Rothschild. This auction has illustrated that the city is full of 'super-collectors' with unlimited financial resources to secure what is regarded as the best within the wine world. In essence, the withdrawal of the wine duty has not only revolutionized Hong Kong's drinking culture and alcohol industry; it has had a huge knock-on effect in the wine trade in mainland China and the wine world at large.

Although trade figures present a clear case that Hong Kong has transformed into a significant wine-trading hub, academic discussion of the development of Hong Kong's wine trade has been limited. Moreover, there is very little qualitative data to explain the transformation of such a newly emerged industry. Therefore, this chapter uses Hong Kong as a strategic geographic location to study the globalization of wine for two major reasons. First, Hong Kong is a global financial centre, the freest economy in the

\footnotetext{
${ }^{1}$ Exchange rate at $f 1$ to $H K \$ 11.5$ and $\$ 1$ to $H K \$ 7.78$ is used throughout this chapter.
} 
world (Miller, Kim and Roberts 2018) and a well-established logistic hub, which allows the import of wine into the now postcolonial city-state. Second, not only is Hong Kong an interesting and important place to study because the city demonstrates the globalization of wine processes from the economic, social and cultural perspective within a part of East Asia, but more importantly, it is within this context that a large volume of wine is subsequently being re-exported to mainland China. Hence, Hong Kong is a crucial access point for the constant flow of global goods and culture.

\section{Theoretical background}

Academic literature has discussed research on alcohol consumption and, more specifically, the geographies of wine from anthropological, historical and technical perspectives. There is a large body of wine literature on production (e.g. Holly 1994; Orr 1995; Santon 1996; Simpson 2011), appellation (e.g. Gade 2004; Moran 1988, 1993, 2001) and terroir (e.g. Atkinson 2011; Dion 1959; Unwin 1991; Whalen 2010; van Leeuwen and Seguin 2006). Moreover, Dougherty's (2012) edited book on the Geography of Wine features a number of examples regarding wine in relation to the cultural, regional, physical, economic and technical context, and advances our current understanding of the Canadian wine tourism sector (Carmichael and Senese 2012), the physical and cultural characteristics of terroir in Burgundy and Bordeaux (Lemaire and Kasserman 2012), viticulture in California (Elliott-Fisk 2012), and how GIS (geographical information systems) and remote-sensing techniques can be deployed to manage vineyards (Green 2012; Johnson et al 2012), and so on.

Others have also written about the globalization of wine from a historical perspective. For example, Simpson (2011) explores the development of the wine industry in Europe between 1840 and 1914. Findings illustrate that phylloxera, a pest that damages the roots and leaves of grapevines, distorted the production and consumption of wine in France. Subsequently, the decline of the French wine industry created opportunities in Spain. By the late 1880s, a third of wine produced in Spain was exported to France (2011: 264). Regarding the wine trade, other works discuss the impact of networks and industrial districts in the English wine industry (Turner 2009), and industrial clustering in the Paso Robles wine region (Beebe et al 2013). In terms of wine consumption, other research also illustrates that wine concerns authenticity, taste and democratization (Smith Maguire 2018), as well as the projection of social identity, class and economic position (e.g. Ho 2015; Järvinen, Ellergaard and Larsen 2014; Rössel and Pape 2016).

However, despite the large amount of existing literature on wine, much of it is AngloEuropean focused, with little attention paid to East Asia's wine market in general, and Hong Kong's growing wine industry specifically. In order to fill this gap, this chapter aims to provide a general understanding of the globalization of Hong Kong's wine industry in three ways. First, it looks at existing theories and methods on how research on alcohol and wine in Hong Kong and France has previously been carried out (e.g. Demossier 2005; Ho 2015; Ma 2001; Smart 2005). Then, through the analysis of wine trade figures and ethnography of wine fairs, as well as interviews with professionals who work for the industry, this chapter explores the Hong Kong wine industry from 
both the local and global perspectives. Moreover, theories of indigenization (Appadurai 1996; Miller 1998), cultural capital (Bourdieu 1984) and conspicuous consumption (Veblen 2000 [1899]) are also applied to understand the localization (i.e. using a local form of culture to transform a foreign product into a more acceptable one) of wine in Hong Kong.

\section{Research methods}

This chapter draws on data collected between 2009 and 2015 during various visits to Hong Kong. Participants were contacted through personal and professional networks in which the non-random sampling of 'snow-balling technique' was applied to recruit a wider and larger sample size. Specifically, thirty semi-structured interviews were conducted between 2009 and 2010, with follow-up interviews carried out in the following years. Ten of those were categorized as strategic or elite interviews, as they were conducted with government agencies, high-end hotel restaurant employees, wine connoisseurs, wine traders and bar managers. The rest were conducted with local Hong Kong, as well as international, consumers from Australia, England, France, Germany, Scotland and so on. Participants included IT professionals, teachers, business owners, hedge fund managers, artists, exchange students and pensioners.

Four additional focus groups also took place, with a total of twenty-five participants who were asked to share their experience of wine-drinking practices and their understanding of the wine market. Interviews and focus groups were carried out in English as well as Cantonese. When permission was granted by the participants, recordings were made for transcription and analysis by the author. At times when participants declined to be recorded, interview notes were taken instead.

Furthermore, ethnographic research was carried out in wine bars, specialist wine shops and wine-tasting events. An ethnographic approach towards studying the wine trade has proven to be effective. For example, Demossier (2005) attended wine fairs in France and explored wine consumption, which provided an effective method for studying the interactions between suppliers, buyers and consumers. Similarly, I attended wine fairs and trade shows in Hong Kong and conducted participant observation, as well as conducting informal interviews with representatives and visitors from different parts of the world.

Names provided in this chapter are pseudonyms to ensure anonymity. The analysis of materials including marketing brochures, auction house catalogues and newspaper adverts in both Chinese and English was also included in the data gathering and analysis phase of the research. Local knowledge and language skills of the author were essential when accessing critical informants and analysing various marketing materials.

\section{The wine industry in Hong Kong and emerging wine businesses}

The chapter is structured as follows. First, it studies the operation of the wine trade in Hong Kong and mainland China through looking at how new companies have emerged 
to serve this emerging wine market. Second, it explores the popularization of wine consumption in Hong Kong in relation to changing consumption patterns. Third, it goes into the discussion of the changing levels of wine knowledge and education. Fourth, it demonstrates the local branding and tasting of wine through studying how a global product such as wine can be localized in the Hong Kong context. The chapter ends with a discussion of how globalization has not just changed the drinking culture in Hong Kong, but also how the global wine trade has evolved because of the globalization of cultural consumption.

In Hong Kong, the drop in the wine duty alone would not have transformed the city into one of the most important wine-trading hubs in the world. I argue that three government agencies - namely InvestHK, the official foreign direct investment (FDI) agency, the Hong Kong Trade and Development Council (HKTDC) and the Hong Kong Tourism Board - have been working together to come up with mechanisms, strategies and events that have enabled the promotion of the wine trade.

For example, InvestHK has been working closely with a number of global wine businesses, educators and equipment providers to set up their presence in Hong Kong. Specifically, they give advice to investors on employment recruitment processes, labour legislation, the tax regime, office rental and warehousing. One of the most significant investment projects is by a Canadian investor who set up the winery Ap Lei Chau (an island in Hong Kong). Since Hong Kong's climate is not suitable for vine cultivation, grapes are being imported for winemaking. Although this is a small-scale production aimed at the hotel and catering industry, the concept of 'Made in Hong Kong' has made a positive contribution regarding how the world sees the local wine industry.

From the global wine trade perspective, the HKTDC and Hong Kong Tourism Board also organize international-scale events to provide platforms for business-to-business (B2B) and business-to-consumers (B2C) interaction. Two large-scale annual events have been taking place since 2008: the Hong Kong Wine and Dine Festival (formerly known as the Food and Wine Festival) and the Hong Kong International Wine \& Spirits Fair have played important roles in promoting wine tourism, education and trade on the global scale. Exhibitors from wine-associated sectors, including wine ware, packaging, logistics, storage, wine education and catering have also been participating.

According to trade figures (Hong Kong Trade Development Council 2008), the Wine \& Spirits Fair hosted 240 exhibitors from twenty-five regions and countries, and 8,758 buyers from fifty-five countries and regions in 2008. The last day of the event was open to the general public and 10,096 visitors attended. The exact figures are not available for the 2009 event, but in 2010 it was reported that nearly seven hundred exhibitors from thirty countries and regions took part in the fair. In addition, the fair was attended by more than 14,000 buyers, a 19 per cent increase from the previous year. The four biggest buyer increases in terms of buyers' countries of origin were Japan (39 per cent), the United States (23 per cent), Australia (22 per cent) and mainland China (16 per cent). The last day of the event was open to the general public and attracted over 14,000 visitors, a 15 per cent increase from the previous year. By 2014, the Wine \& Spirits Fair was attended by approximately 20,000 buyers from seventy-five regions 
and countries (Hong Kong Trade Development Council 2015a). These figures illustrate that Hong Kong's wine trade continues to grow, and that consumers as well as the trade are now looking beyond France and beginning to purchase wine from other countries.

While HK\$1.60 billion ( $₹ 139$ million, $\$ 206$ million) worth of wine was imported in to Hong Kong in 2007, this figure increased more than fivefold to HK\$ 8.40 billion ( $£ 730$ million, $\$ 1.10$ billion) by 2014 (Hong Kong Trade Development Council 2015b). Similarly, the volume of wine imports has increased by two and a half times to 52.4 million litres by 2014 . The differing ratio between the increase in import value by the factor of five and volume by the factor of around 2.5, that is at two to one, suggests that Hong Kong is keen to purchase more expensive, fine and rare wines for which the global prices have increased significantly over the last few years. French wine is by far the most popular wine in Hong Kong, accounting for 52 per cent of the overall import value in 2014. More surprisingly, the UK was the second biggest exporter of wine to Hong Kong at almost 11 per cent. However, this was not necessarily because of its wine production, but was rather due to the fact that most fine and rare wines are sold through auction houses in London.

Despite Hong Kong being a valuable wine-trading hub that has seen a significant growth of local wine drinkers, both local and international wine merchants see Hong Kong as a strategic market, but not necessarily the final market destination. In the first nine months of 2015, around 90 per cent of the wine that was being imported to Hong Kong was re-exported to Macau and mainland China (Hong Kong Trade Development Council 2015b). The key reason is that the growing middle class in mainland China is increasingly interested in drinking wine. Regarding Macau, the casino industry is closely linked to the wine industry, because casinos need large quantities of wine for their customers. However, when the casino industry underperforms (e.g. in 2014), the sales of wine also decrease. Nonetheless, merchants still prefer to invest in the mainland through Hong Kong, and this is due to Hong Kong's robust financial, legal and logistical infrastructure. In order to get a better understanding of how to set up a wine business in Hong Kong, a case study is now presented, concerning how Georgia, a local Hong Kong woman, recently started a wine business with the intention of capitalizing on the wine boom.

Similar to other newly-established wine businesses in Hong Kong, Georgia exports a large volume of products to mainland China, but finds that supplying wine to mainland China is challenging. First, just like conducting other businesses in the mainland, it is difficult to gain access to networks without guanxi, a term in Mandarin which loosely translates into the notion of 'relationship'. Her company previously worked with a largescale supermarket chain in Hong Kong, which already has a strong presence in the mainland. As a result, through existing business contacts, Georgia was able to use the already-established distribution channels and supply chains to transport goods across the border.

Second, as a result of corruption practices, Georgia's company also employs 'agents' to ensure trouble-free transactions. Exporting goods from Hong Kong to China is usually carried out by a third-party company, which may charge between 3 and 7 per 
cent of the value of the shipment. Georgia said that shipping three tonnes of goods may cost around HK\$1,500 ( $£ 130, \$ 193$ ), but a further HK\$750 ( $£ 65.2, \$ 96.4$ ) would be charged as a 'handling fee' by agents. The company sells wine in large volume to mainland China, usually in containers capable of holding up to 1,000 bottles. The profit margin for this kind of low-cost French wine is around HK\$5.00 to 10.00 (£0.43-0.87, $\$ 0.62-1.29$ ) a bottle, and each bottle will then be retailed for between HK\$30.0 and $\$ 40.0$ ( $2.61-3.48, \$ 3.86-5.14$ ). A number of mainland Chinese businesses have been known to purchase a container of wine as a one-off investment in the hope it can be resold at a much higher value.

Georgia also explained that the number of bottles declared on export documents sometimes does not correspond to the actual number being shipped. Two 'books' are usually kept at the company warehouse, one to show to the customs officers and the other containing the actual figures, which are higher than the ones stated in the official export documents. It would be difficult to generate profits if the actual figures were declared.

In addition to supplying wine to mainland China, Georgia's company also trades with local Hong Kong businesses. She also works with bartenders in order to get her products marketed - the bar staff receive a percentage of the profit if the wine is sold. Hence there is an incentive for them to promote her products. This newly established wine business tells us that breaking into the wine industry is not an easy task. Although Hong Kong has a robust legal and trading system, which eliminates the practice of corruption, doing business in mainland China remains challenging. In addition to the problems of corruption, China is notorious for producing and distributing counterfeit goods, and customers are aware of the existence of fake wines. Those wines can be made from chemicals, or in some cases cheap wine is bottled in used expensive bottles to trick customers. A Hong Kong-based informant said there is now an underground market in both Hong Kong and mainland China in which empty bottles of fine and rare wines can be traded for a considerable amount of money for refilling purposes.

As the wine trade begins to mature in Hong Kong, local wine businesses have to adapt. Another informant who runs a wine business said that when the wine industry took off in 2008, a large quantity of low-quality wine was being imported to Hong Kong, and these French wines being sold by new businesses were often considered unsaleable in France. These wines would have been destroyed or distilled into alcohol for other uses. Yet the same wines proved popular and profitable in Hong Kong and the mainland. But as local consumers are becoming more knowledgeable, they have begun to demand higher-quality wine, a trend which is also being reflected in the valueto-volume ratio already mentioned above.

\section{The popularization of wine consumption in Hong Kong}

Exploring marketing materials of wine exhibitions and trade fairs can tell us about the image of wine that the industry aims to project. For example, from the official promotional leaflet of the Hong Kong International Wine and Spirits Fair in 2011, it can 
be seen that the focus of the map is on the Asia Pacific region. The front cover of a similar event brochure presents two trendily dressed couples, one of Chinese origin and the other one of European origin. All appear to be cheerful, holding a glass of red wine, toasting each other. This implies that wine is not just trendy and stylish, but also represents cosmopolitanism. The background is presented with the skyline of Hong Kong Island in which the International Financial Centre building particularly stands out. In this version of the brochure, the content is written in both Japanese and Chinese, which corresponds to the importance of both markets. An English version of this brochure was also available. This brochure gives the impression that Hong Kong is a rich, stylish and cosmopolitan city where the West meets the East.

Another leaflet which was also being handed out to visitors places the emphasis on the promotion of Hong Kong's wine trade. This leaflet illustrates three important messages. First, the label shows Hong Kong's skyline, and the description reads 'Hong Kong Asia's wine capital', which gives the impressions that Hong Kong is now a key wine-trading hub. Second, '0.00' is printed on the 'price tag', which represents Hong Kong's zero per cent wine duty rate. Third, 'Magnum Force' refers to a $1.5 \mathrm{~L}$ magnum bottle, illustrating that the wine trade in Hong Kong is large and growing. Importantly, it is also a pun that refers to Clint Eastwood's film Magnum Force where Eastwood plays the violent policeman called Dirty Harry. It could be interpreted that the joke aims to connect wine to the glamour of Hollywood productions.

Along with the changing marketing image of wine in Hong Kong, local alcohol consumption patterns have also been transformed. For many decades Chinese rice wine was a popular drink in Hong Kong. Although it was often consumed as an alcoholic drink by male manual labour workers as well as other members of the working-class population, it was also used in the making of traditional Chinese medicine, domestic cooking and ancestral worshipping rituals (Ho 2015).

Post-Second World War Hong Kong was poor, but with the growing manufacturing, real estate and electronics industries in the 1960s and 1970s, Hong Kong became wealthy. Some forms of Western cultural consumption and culinary practice have been adopted, since there have long been Europeans working in Hong Kong. For example, cognac is expensive, of French origin, and often perceived as the symbol of wealth and status in Hong Kong (Smart 2005) as well as in other parts of the world. For almost five decades, cognac was the choice of drink in birthday celebrations, wedding banquets and business meetings. At the same time, since Hong Kong is a former British colony, some forms of Western drinking culture were also introduced by the British in workplaces. For example, one retired Hong Kong policeman said that drinking was used as a way to bridge the hierarchy between the Hong Kong locals and British policemen within the Royal Hong Kong Police Force. Disagreements among colleagues often occurred during work, but after-work social events which involved alcohol consumption gave opportunities to junior and senior colleagues to discuss openly work-related as well as personal issues. Through research on the longshoremen working community in Newfoundland, Canada, Mars (1987) argues that drinking acts as a feature of social hierarchy, inclusion, exclusion and social identity. Similarly, in the Hong Kong police context, drinking became a way for colleagues of 
different ranks to establish social bonds. Drunkenness also allowed the temporary removal of work hierarchies.

Other types of alcohol such as imported European beers (Ma 2001) and whisky were popular, but wine remained expensive and was only offered in high-end restaurants and specialist shops. With the popularization of North American and Western European popular culture in the 1980s, wine was perceived as a drink associated with class, sophistication, and high culture. In Bourdieu's (1984) terms, it was a form of cultural capital which was socially legitimate.

Perhaps it is also important to acknowledge the existing drinking culture today. For example, younger consumers tend to be less superstitious and do not place much emphasis on traditional customs. But older drinkers may avoid white wine at weddings and birthday gatherings, as white is traditionally associated with the dead. In contrast, red wine is more widely accepted, not only as a fashionable drink, but also because red represents good luck.

In one focus group made up of eight local consumers (men and women aged between their forties and sixties), all of the participants agreed that beer is slowly being replaced by red wine when people dine out in local Chinese restaurants. This is driven by the cost of wine having become significantly lower. Moreover, they believed that drinking wine has become more commonplace in Hong Kong, while rice wine is going out of fashion because 'it tastes awful'. In other words, social factors have contributed to how taste is being perceived: some consumers think that rice wine tastes awful, rather than rice wine becoming awful-tasting recently. This is due to a shift in the taste culture, as well as changes in habitus and the perception of cultural capital (Bourdieu 1984).

According to interviews with two experienced employees of a five-star hotel in Hong Kong, a connoisseur and a French restaurant manager, there is a group of wealthy local elite people who have been collecting wine for decades. Traditionally they bought wine through overseas auction houses, and stored their collections, mostly of French origin, in the UK. The purchase would then be shipped between 10 and 15 cases at a time from overseas warehouses to Hong Kong, for consumption or personal collection. The wine would be taxed accordingly at 80 per cent. They also explained that wine has been served in luxury hotels for many years. When wine tax was at 80 per cent, a bottle of wine that cost $\mathrm{HK} \$ 100$ (£8.70, $\$ 12.90$ ) from an overseas supplier would be HK\$180 ( $£ 15.70, \$ 23.10$ ) when import tax was added. With mark-up and overheads, that bottle would be listed on the menu at $\mathrm{HK} \$ 800$ ( $£ 69.60, \$ 103$ ), about eight times the import price. This has now changed with the popularization of wine and the withdrawal of wine duty, and wine is now available in most restaurants. Regular customers sometimes prefer to have their wine collections directly shipped to the restaurant, but those tend to be fine and rare wines which the hotel may not supply. In such cases, a corkage fee is imposed, as is usual.

For many Hong Kong consumers, France was traditionally perceived as the most prestigious wine-producing country, and during my visit to wine fairs and trade shows in Hong Kong, many exhibitors came from France. Based on discussions with a number of exhibitors, the general feedback was that visitors were overly enthusiastic about tasting French wines and most of the visitors flocked to these stands, resulting 
in several 'scuffles' and altercations. A representative from the Rhône-Alpes Regional Council (Entreprise Rhône-Alpes International), who was in attendance to promote wines from that region, said that his stand was popular. Visitors were keen to try the wine due to the Rhône's association with France. The council has also established a regional office in Shanghai, and acknowledges that mainland China is one of their key targeted markets. There were also Hong Kong suppliers specializing in French wine, including one which specialized in selling wines from Saint-Émilion.

In addition, there were a number of wine suppliers attending these events from countries less renowned in Hong Kong for wine production, such as Argentina, Australia, Austria, China, Germany, Italy, Portugal, Spain, New Zealand and the United States. Although these wines were often of good quality, the stands were less popular with consumers because they were unfamiliar to them. The marketing manager of the Austrian Wine Marketing Board (Österreich Wein Marketing GmbH) said that they supplied wines to a number of local hotels, but consumers' lack of knowledge about these wines made it difficult to sell their products.

Gender plays an important role when choosing wine. Alcoholic drinks were often perceived as a male preserve in traditional Chinese society. Many trusting friendships were established through drinking. At the same time, alcohol would also be drunk before battles against enemies and after victories. Thus alcohol has played an important role in Chinese history. In comparison, women who drank alcohol in the public sphere were most likely to be seen in brothels and often were regarded in a negative way. However, these views have been changed with the globalization of consumer culture.

Mary, a participant in her mid-twenties who grew up in different parts of the world, believed that women now drink more wine than men in Hong Kong. She had many single female friends in their late-twenties who would like to meet men. This group of women believed that they would look and feel more 'attractive and sophisticated' if they held a glass of wine in a bar, rather than drinking a large glass of beer. Moreover, her friends were health conscious, as is Mary herself (she is a personal trainer). Generally speaking, a glass of wine contains fewer calories than a glass of beer.

Furthermore, it is more difficult to share a beer or cocktail, and therefore drinking wine seems to act as a social practice, as a bottle can be shared among a group of friends. It is of course possible to share a round of drinks with friends, but this could lead to overconsumption of alcohol if there is a large group involved and everyone feels obliged to buy a round of drinks. In addition, some may feel obliged to spend money on a round of drinks, while what they actually want is to have one drink. Mary also believed that Chinese women 'can catch up quicker than men on wine drinking, because a lot of Chinese girls who come back from overseas tend to date Western men'. Therefore they are more likely to go out for Western-style meals and social events. As a result, these women have a higher exposure to wine consumption. Chinese women also tend to feel more comfortable and act more at ease when drinking wine than other alcoholic drinks. In contrast, Mary had not come across many Chinese men dating Western girls. To these men, as she described it, 'it is probably harder to learn about wine'. Perhaps her views are slightly biased, as there are local 
men who are also knowledgeable about wine and who have been attending wine courses and wine-tasting events. Nonetheless, wine is deemed as a popular drink with local women. Informants from another focus group also claimed that while men prefer dry wines, women tend to go for sweeter wines. White wine seems popular with women according to some, but this claim contradicts other participants' views that red wine is popular among women. Some customers may not be familiar with ordering wine, but nevertheless it remains a popular choice when dining in local Chinese restaurants and drinking at bars.

\section{Changing levels of wine knowledge and education}

We have so far discussed the popularization of wine in Hong Kong and illustrated the changing alcohol consumption patterns. The key finding so far demonstrates that local consumers' affection for French wine is apparent, and because of this, they are reluctant, or lack the knowledge, to explore other wines. But as consumers are becoming more educated, they begin to take courses in wine-tasting and explore wines of other countries. This section further discusses Hong Kong's emerging wine education and wine culture.

Anthropologists view alcohol consumption as a way of constructing meanings, and Douglas (1987) in particular describes this through the notion of 'constructive drinking'. Similarly, there are two reasons as to why consumers in Hong Kong may want to pursue wine drinking to construct social meanings: to acquire cultural capital (Bourdieu 1984), and to carry out conspicuous consumption (Veblen 2000 [1899]). Both ideas are related to the display of identity and knowledge, and having the financial ability to consume a product.

Bourdieu (1984) defines three forms of capital with regard to social class, which are economic, social and cultural capital. He further defines three forms of cultural capital: embodied, objectified and institutionalized (Bourdieu 1984: 47). The key argument is that cultural capital is not a form of knowledge that can be acquired in a short period of time. Developing such forms of capital requires time and resources. Furthermore, skills and knowledge can be defined as cultural capital, which are institutionalized because one's knowledge can be accredited through attending an educational establishment.

Bourdieu's notion of cultural capital allows us to understand why consumers may want to learn about traditional wine-drinking practices, but we can also use Veblen's (2000 [1899]) theory of conspicuous consumption to explore the ways in which drinkers purchase expensive wine in Hong Kong. Conspicuous consumption has become one of the most discussed topics within the consumption framework. Through observations in nineteenth- and early twentieth-century North America, Veblen describes the way in which upper classes carried out luxury shopping to flaunt their wealth. As such, these 'are methods of demonstrating the possession of wealth' (Veblen 2000 [1899]: 40). Conspicuous consumption is a waste of time and effort, as well as a waste of goods. In addition, objects are used to communicate meanings and to portray one's wealth and social status (1899: 31-7). This was particularly important to the 
entrepreneurs who became wealthy quickly during the industrial boom periods. This class acquired tremendous wealth in a short amount of time and, as a result, also resorted to conspicuous consumption. They often mimicked the way that the upper class consumed, a practice Veblen referred to as emulation. Along these lines, some consumers in Hong Kong may choose to consume expensive alcohol in order to flaunt their wealth in bars and restaurant. However, wine consumption requires cultural capital, which some consumers may lack, and taking part in a wine-tasting course will compensate for that.

The increased availability of wine in Hong Kong has led to consumers wanting to learn about wine drinking, and new wine businesses are being established to cater for these new consumers who emerged when the wine trade took off. In 2008 there was a lack of recognized wine experts in Hong Kong. It is important for the professionals who work in the industry to have a strong understanding of the products that they offer to their customers. One informant describes such issues when dining at a local restaurant: 'If you ask the waiter about what dishes go with what kind of wine, he probably wouldn't be able to tell you.' This tends to be true because waiting staff do not usually have the adequate training or knowledge to make suggestions to customers. According to field observations, a number of local restaurants had only begun selling low-quality red and white wine. On various occasions, wine options were limited, and some restaurants in particular only offered two choices: house red and house white. But this is changing as restaurant staff become better trained and informed about wine. At the same time, many local and global wine connoisseurs have recently emerged. Wine-tasting courses are now widely available. Most notably, the Open University of Hong Kong and the University of Hong Kong School of Professional and Continuing Education (HKU SPACE) have introduced professional diploma and certificate programmes for those who work in the wine and related industries, and for those who want to learn more about wine in general. Many restaurants now also run food and wine matching events for enthusiasts.

Running wine fairs is also a good way to promote wine education and knowledge. I collected marketing materials on wine education during wine fairs and events. For example, one brochure advertises a workshop on 'wine tasting technique' run by the Hong Kong Management Association. The front page reads, 'Learn how to taste and how to talk about it', and this idea perfectly fits into Bourdieu's notion of acquiring cultural capital. More importantly, it relates to the overarching theme of the wine field as highlighted in this book (see Chapter 1). The two two-and-a-half-hour evening workshops cost $\mathrm{HK} \$ 2,000$ ( $£ 174, \$ 257)$ for members and HK\$2,200 ( $£ 191, \$ 283)$ for non-members. The course is taught in Cantonese, even though the advert is in English. Another brochure advertises a diploma course in 'Wine Business'. This diploma is made up of seven modules, and each module costs $H K \$ 2,850$ ( $£ 248, \$ 366$ ) for members and HK\$2980 ( $£ 259, \$ 383$ ) for non-members. Wine tasting courses on wine from specific countries and regions such as California and Bordeaux are also available. These brochures promote the idea of wine education, and the courses are mostly designed for those who have no prior knowledge of wine but would like to learn. We can clearly identify from the printed materials that wine consumption is portrayed as a Western practice - very little Chinese is being used on such materials. 
When wine was becoming popular in Hong Kong in 2008, only Bordeaux was perceived as the preferred choice. As consumers have become educated and adventurous, they have moved beyond drinking wines of the Old World such as France, Germany and Italy, to the New World, including Argentina, Australia, Chile and New Zealand and the United States. Now wine can easily be bought from supermarkets and convenience stores, which would have been previously impossible. As wine has become increasingly popular, consumers are not only interested in purchasing expensive cognac or fine and rare wine to display their wealth, which in Veblen's terms is conspicuous consumption. They are also aspiring to accumulate cultural capital through developing wine knowledge, and subsequently developing cultural capital in wine for its own sake.

\section{Local branding and tasting of wine}

Globalization has also allowed the constant exchange of goods and cultures between the local and global context. In particular, one product that stood out at the Hong Kong Food and Wine Festival was the 'Hello Kitty' wine, which captures the importance of local branding and marketing in order to appeal to local cultural tastes. The promotional banner at the stand reads 'Hello Kitty Wine'. Underneath, it has a pink Hello Kitty figure, and below that, it reads 'Made in Italy'. 'Imported from Italy' is also printed in traditional Chinese for those who may not read English. Both male and female customers showed interest in this product. This kind of product has a certain appeal in South East Asia because of a perceived 'cuteness'.

A point that has been overlooked in previous studies involves cultural differences in consumption, or, in this case, subcultural differences. Products with Japanese cartoon characters such as Mario, Astro Boy and Doraemon, as well as characters by Western artists including Miffy, Snoopy and Forever Friends, are popular in Hong Kong, Japan and South Korea. Not only are there a number of shops which specifically sell cartoonthemed merchandise including T-shirts, bags, wallets, dolls, photo albums, notepads, pens and so on, but they also attract a wide range of customers from different age groups. Miller (1998) uses the example of consumption of Coca-Cola in Trinidad to demonstrate how a product can be indigenized such that the end-product is no longer global (American) but rather local (Trinidadian). Using a similar understanding, we can say that Italian wine is also being transformed. It is localized, and stops being only a product of Italy, through the use of the packaging of the Japanese cartoon character, and subsequently being marketed in Hong Kong. Appadurai (1996) has theorized the notion of globalization as indigenization. He argues that under the influence of globalization, things appear to be homogeneous, but it is the localization of global trends which allows these things to become more acceptable to a particular local society. Therefore, wine drinking, which is often perceived as a form of high culture, is being popularized through a Japanese cartoon cat that has made the product from the West more acceptable to Hong Kong consumers.

It is common to see both adults and children wearing items with distinct designs such as Hello Kitty and Paul Frank in Hong Kong. Such practices for adults might be alien to Westerners and perceived as childish, but for the locals this is an expression of 
identity and 'cuteness'. Conversely, one frequently comes across female teenagers in the UK wearing clothing items which often convey a sense of mature femininity. These could be perceived by a different culture as vulgar. Therefore, consumers' practices within particular cultures should be commented on with caution. In addition, emotions (Colls 2004) can be communicated through objects, and I argue that a bottle of wine with Hello Kitty labelling is likely to be bought as a gift and given to younger women. Once again, this kind of product seems to be popular in the South East Asian regions, but may struggle to sell in other parts of the world.

To elaborate on the concept of indigenization, the Hello Kitty branding of wine communicates three key messages simultaneously. First, it can be understood as a local product, as it is aimed at certain types of Hong Kong consumers, presumably younger women. Second, it is also perceived as a regional product, because cartoon branded items are well regarded in South East Asia. Third, the imagery of Hello Kitty has also been promoted around the world. Essentially, a bottle of Italian wine with Hello Kitty branding demonstrates a process of globalization that cuts across national cultural boundaries. From the above observations, although we can see that Hong Kong is largely a globalized city within which Western forms of consumption are widely accepted, more local cultures and customs are also important when a new product or idea is being introduced.

\section{Conclusion}

From wine being only a product for very wealthy Hong Kong consumers, to now being a drink served in most restaurants, the local wine culture has been transformed in less than a decade. It is undeniable that Hong Kong's continuous growing demand for wine has pushed up the prices of rare vintages, and this trend is being reflected in recordbreaking wine auctions taking place in Hong Kong. The domination of imported beer, cognac and whisky is now being replaced by mostly red wine, but white wine has also become more popular. This was made possible when the wine duty was completely removed in 2008. However, I argue that the transformation could not have been achieved without the support offered by three Hong Kong government agencies, namely InvestHK, the Hong Kong Trade and Development Council and the Hong Kong Tourism Board. Together they have been hosting events to create platforms for wine businesses and consumers to interact within.

When combined with the change in the tax regime, this kind of government-backed trade promotion has proven to be effective when creating a new industry, that of wine. Perhaps other industries can also be created using a similar model. Trade figures illustrate that the wine trade is growing, specifically with more high-quality wine being imported to Hong Kong. In addition, with Hong Kong being the gateway for the mainland's wine trade, a large quantity of wine is being re-exported for the growing Chinese middle class. Although the mainland market accounts for most exports in Hong Kong, questionable business practices such as corruption may yet discourage foreign investors investing in it directly. 
The popularization of wine has also illustrated changing trends in alcohol consumption patterns in Hong Kong. More specifically, we see a shift from cognac consumption to wine consumption, from elite consumers to middle-class consumers, from wine being difficult to purchase to a wider range of wine being available in more outlets, from older to younger consumers, from male to female consumers, from red wine to white wine consumption, from France to other countries, and so on. Wine has become a mass phenomenon, and at the same time the market itself has become more diversified, with new types of consumers constantly emerging.

With wine being more widely available, local consumers have developed a desire to take courses in wine appreciation. They want to be seen as wealthy by flaunting the financial ability to purchase expensive wine through conspicuous consumption (Veblen 2000 [1899]). But more than this, sophisticated consumers want to show their knowledge of food and wine pairings in social settings, and this behaviour can be understood as the display of cultural capital (Bourdieu 1984). Therefore, wine education providers have emerged in Hong Kong, teaching drinkers how to taste wine. With consumers being more educated, they have gone beyond drinking wine from France, which was traditionally associated with prestige and authority. This trend is reflected by trade figures illustrating that the sales of wines from the New World are growing. Another way of thinking about the globalization of cultural consumption is through the notion of indigenization (Appadurai 1996; Miller 1998). The example of Hello Kitty wine captures the glocalization of culture, in which the meaning of a product can be transformed from its place(s) of origin to a new location. Marketers should pay attention to such factors when they introduce a product to a new region.

In short, Hong Kong is a strategic geographic location which helps us understand the globalization of wine, both within Hong Kong itself and through its acting as a connection point between mainland China and the West. Wine has become a popular drink in Hong Kong because it captures the notions of high culture, flaunting wealth and being Westernized. This chapter has shown how wine consumption practices have changed over the years, and how the global wine trade has adapted itself to serve the newly-emerged Hong Kong and mainland Chinese markets.

\section{Acknowledgements}

Earlier versions of this research were presented at the Foodscapes: Access to Food Excess of Food conference organized by the University of Graz, Austria, at the Castle of Seggau in September 2013, and The Worlds in a Wine Glass conference organized by the University of Newcastle, Australia, at King's College London, UK, in May 2016. The author would like to thank the University College London Graduate School, University College London Department of Geography, and Swedish Research Council (Vetenskapsrådet) for their funding of the project this chapter is based upon.

The author would like to thank the Department of Social and Economic Geography at Uppsala, Sweden for their academic support. The author would also like to thank the editors whose comments and suggestions helped improve this chapter. Additionally, the author would like to thank all the participants who took part in this research. 


\section{References}

Appadurai, A. (1996), Modernity at Large: Cultural Dimensions of Globalization, Minneapolis: University of Minnesota Press.

Atkinson, J.M.W. (2011), 'Terroir and the Côte de Nuits', Journal of Wine Research, 22(1):35-41.

Beebe, C., Haque, F., Jarvis, C., Kenney, M., and Patton, D. (2013), 'Identity Creation and Cluster Construction: The Case of the Paso Robles Wine Region', Journal of Economic Geography, 13:711-40.

Bourdieu, P. (1984), Distinction: A Social Critique of the Judgement of Taste, London: Routledge.

Carmichael, B.A., and Senese, D.M. (2012), 'Competitiveness and Sustainability in Wine Tourism Regions: The Application of a Stage Model of Destination Development to Two Canadian Wine Regions', in Dougherty, P.H. (ed.), The Geography of Wine: Regions, Terroir and Techniques, Dordrecht: Springer, 159-78.

Colls, R. (2004), '“Looking Alright, Feeling Alright”: Emotions, Sizing and the Geographies of Women's Experiences of Clothing Consumption', Social and Cultural Geography, 5(4):583-96.

Demossier, M. (2005), 'Consuming Wine in France: The "Wandering" Drinker and the Vin-anomic', in Wilson, T.M. (ed.), Drinking Cultures: Alcohol and Identity, Oxford: Berg, 107-28.

Dion, R. (1959), Histoire de la vigne et du vin en France: des origines au XIXe siècle, Paris: Les Belles Lettres.

Douglas, M. (1987), Constructive Drinking: Perspectives on Drink from Anthropology, Cambridge: Cambridge University Press.

Elliott-Fisk, D.L. (2012), 'Geography and the American Viticultural Areas Process, Including a Case Study of Lodi, California', in Dougherty, P.H. (ed.), The Geography of Wine: Regions, Terroir and Techniques, Dordrecht: Springer, 49-57.

Gade, D.W. (2004), 'Tradition, Territory, and Terroir in French Viniculture: Cassis, France, and Appellation Contrôlée', Annals of the Association of American Geographers, 94(4):848-67.

Green, D.R. (2012), 'Geospatial Tools and Techniques for Vineyard Management in the Twenty-first Century', in Dougherty, P.H. (ed.), The Geography of Wine: Regions, Terroir and Techniques, Dordrecht: Springer, 227-45.

Ho, H.K. (2015), 'Hong Kong', in Martin, S.C. (ed.), The SAGE Encyclopedia of Alcohol: Social, Cultural, and Historical Perspectives, Thousand Oaks, CA: Sage, 701-03, DOI:10.4135/9781483331096.n258.

Holly, P. (1994), 'Organisational Structure of Wine Production in the US', Journal of Wine Research, 5(2):91-101. 
Hong Kong Trade Development Council (2008), A World of Fine Wine, http://hkwinefair. hktdc.com/dm/200812/issue01.htm (accessed 26 November 2018).

Hong Kong Trade Development Council (2015a), Asia's Premier Wine Event Draws to Successful Close: Global Wine Merchants Set Sights on Asia Expansion, http://www.hktdc.com/fair/hkwinefair-en/s/8843-For_Press/HKTDC-Hong-KongInternational-Wine-and-Spirits-Fair/PressRelease8Nov2015.html (accessed 26 November 2018).

Hong Kong Trade Development Council (2015b), Wine Industry in Hong Kong, http://hong-kong-economy-research.hktdc.com/business-news/article/Hong-KongIndustry-Profiles/Wine-Industry-in-Hong-Kong/hkip/en/1/1X000000/1X07WNW7.htm (accessed 26 November 2018).

Järvinen, M., Ellergaard, C.H., and Larsen, A.G. (2014), 'Drinking Successfully: Alcohol Consumption, Taste and Social Status', Journal of Consumer Culture, 14(3):384-405.

Johnson, L.F., Nemani, R., Hornbuckle, J., Bastiaanssen, W., Thoreson, B., Tisseyre, B., and Pierce, L. (2012), 'Remote Sensing for Viticultural Research and Production', in Dougherty, P.H. (ed.), The Geography of Wine: Regions, Terroir and Techniques, Dordrecht: Springer, 209-26.

Lemaire, D., and Kasserman, D. (2012), 'Bordeaux and Burgundy: A Comparison of Two French Wine Regions in Transition', in Dougherty, P.H. (ed.), The Geography of Wine: Regions, Terroir and Techniques, Dordrecht: Springer, 61-80.

Lister, E. (2011), 'Fine Wine Auctions: Hong Kong Confirms Its Place at Top of the Podium', Financial Times, 17 June, www.ft.com/int//cms/s/0/bc0e571c-989c-11e094d7-00144feab49a.html (accessed 16 February 2016).

Loos, T. (2018), 'For Wine Auctions, It's Been Another Very Good Year', The New York Times, 2 October, https://www.nytimes.com/2018/10/02/arts/wine-auctionsspirits.html (accessed 26 November 2018).

Ma, E.K.W. (2001), 'The Hierarchy of Drinks: Alcohol and Social Class in Hong Kong', in Mathews, G., and Lui, T.L. (eds), Consuming Hong Kong, Hong Kong: Hong Kong University Press, 117-39.

Mars, G. (1987), 'Longshore Drinking, Economic Security and Union Politics in Newfoundland', in Douglas, M. (ed.), Constructive Drinking: Perspectives on Drink from Anthropology, Cambridge: Cambridge University Press, 91-101.

Miller, D. (1998), 'Coca-Cola: A Black Sweet Drink from Trinidad', in Miller, D. (ed.), Material Cultures: Why Some Things Matter, Chicago: University of Chicago Press, 169-87.

Miller, T., Kim, A.B. and Roberts, J.M. (2018). 2018 Index of economic freedom. Washington, DC: The Heritage Foundation. Retrieved from https://www.heritage.org/index/pdf/2018/book/index_2018.pdf (accessed 16 May 2019). 
Moran, W. (1988), 'The Wine Appellation: Environmental Description or Economic Device?' in Smart, R.E., Thornton, R.J., Rodriguez, S.B., and Young, J.E. (eds), Proceedings of the Second International Symposium for Cool Climate Viticulture and Oenology: Auckland, New Zealand, New Zealand Society for Viticulture and Oenology, 356-60.

Moran, W. (1993), 'The Wine Appellation as Territory in France and California', Annals, Association of American Geographers, 83:694-717.

Moran, W. (2001), 'Terroir - The Human Factor', Australian and New Zealand Wine Industry Journal, 16(2):32-51.

Orr, S.C. (1995), 'Production Practices in the Australian Wine Industry', Journal of Wine Research, 6(3):179-93.

Pomfret, J. (2008), 'Asian Wine Auction Uncorks \$8.2 mln in Sales', Reuters, 31 May, https://www.reuters.com/article/arts-hongkong-wine-dc/asian-wine-auctionuncorks-8-2-mIn-in-sales-idUSL3136032920080531 (accessed 26 November 2018).

Rössel, J., and Pape, S. (2016), 'Who Has a Wine-Identity? Consumption Practices between Distinction and Democratization', Journal of Consumer Culture, 16(2):61432.

Santon, T.J. (1996), 'Columella's Attitude towards Wine Production', Journal of Wine Research, 7(1):55-9.

Simpson, J. (2011), Creating Wine: The Emergence of a World Industry, 1840-1914, Princeton: Princeton University Press.

Smart, J. (2005), 'Cognac, Beer, Red Wine or Soft Drinks?' in Wilson, T.M. (ed.), Drinking Cultures: Alcohol and Identity, Oxford: Berg, 107-28.

Smith Maguire, J. (2018), 'The Taste for the Particular: A Logic of Discernment in an Age of Omnivorousness', Journal of Consumer Culture, 18(1):3-20, DOI: $10.1177 / 1469540516634416$.

Turner, S. (2009), 'Networks of Learning within the English Wine', Journal of Economic Geography, 10:685-715.

Unwin, T. (1991), Wine and the Vine: An Historical Geography of Viticulture and the Wine Trade, London: Routledge.

van Leeuwen, C., and Seguin, G. (2006), 'The Concept of Terroir in Viticulture', Journal of Wine Research, 17:1-10.

Veblen, T. (2000 [1899]), 'Conspicuous Consumption', in Lee, M.J. (ed.), The Consumer Society Reader, London: Blackwell, 31-47.

Whalen, P. (2010), 'Whither Terroir in the Twenty-first Century: Burgundy's Climats?', Journal of Wine Research, 21(2-3):117-21. 